\title{
Mapping Commercial and Business Service Occupations by Comparing Qualificational and Factual Requirements
}

\author{
Silvia Annen, Michael Tiemann \\ Federal Institute for Vocational Education and Training
}

\begin{abstract}
Commercial and business service occupations face a number of challenges like demographic change, calls for flexibilization and, especially in Germany, debates about their core profiles. Within a project on similarities and differences between commercial and business service occupations effects of these challenges are analyzed. A threefold approach of theoretical literature studies, a content analysis of initial and advanced training curricula and a survey of over two thousand employees in commercial and business service occupations leads to the development of a framework to describe and systematize these occupations' contents.

These contents can be discerned through different requirements regarding communicative interfaces, use of planning, organizing, regulating, documenting and balancing instruments and systems. A system of categories structuring subject matters and competencies in commercial vocational trainings was developed and with analyzing the quantitative data activities, skills and self-concepts in commercial and business service occupations are identified.

Employees working in commercial and business service occupations show clear trends regarding selfconcepts or aims of their work. But as for single tasks and skills it becomes clear there are differences between several groups of service occupations. Commercial and business service occupations can be discerned by their basic mercantile contents and the aims governing the work.
\end{abstract}

\section{Introduction}

The demographic change, the fall in the birth rate, and the call for flexibilization of occupational careers are giving rise to considerations on reducing the number of initial and advanced training occupations in the German "Dual System". At the same time, with the objective of increasing employment opportunities for those who have completed training, there is a debate on occupational core profiles taking place at the European level. The project on "similarities and differences between commercial and business service occupations" aims at finding a set of common core and comparable qualifications/requirements of service occupations as well as their main differences.

The aim of this contribution is to present the results of a survey of 2.304 employees in commercial and business service occupations. It was conducted to find out more about employees' tasks, skills and selfconcepts. The basis for the hypotheses and the questionnaire design is a systematic analysis of the relevant initial and advanced training curricula. Additionally, data from the German BIBB/BAuA Employment Survey 2012 [4] conducted by the Federal Institute for Vocational Education and Training (BIBB) and the Federal Institute for Occupational Safety and Health (BAuA) are evaluated to answer the research questions.

\section{Body of knowledge}

In the project a theoretical concept of commercial thinking and acting is set up, grounded in a historical and a sociological literature-study. It is aimed at defining merchants' mentality and work capacity and the "cultural difference" between industrial-technical and commercial occupations [3,7]. A second point of reference for the theoretical concept is the analysis of curricula for school-based as well as on the job trainings of all commercial occupations. These include elements of economic-pedagogical theoretical models. The survey data is used to test the theoretically derived assumptions.

Flexible disposition of the commodity work [1], a "market-oriented mode of control" [6: 293] and an increasing focus on customers and services are basic changes in commercial occupations. The selfconceptions of workers trained in commercial 
occupations include an interest to help develop and contribute to the enterprise's interests [11].

The project identified the following as central and ongoing trends influencing commercial and business service trainings and occupations: There is an increasing informatisation of work-processes, which have changed their contours due to international division of labor and cooperation [1]. Also a subjectivication and delimitation of work is seen to take place. The results are a flexibilization of workinghours and -places, work organized in projects, in some branches a filialization of commercial and business service occupations leading to working conditions like in self-employment and precarious job conditions [10]. Another trend is the increase in relationship work in services regarding handling conflicting interests of business and costumers as well as increasing requirements on the quality of services. Service occupations today are formed by a rationalization of processes and a focus of all employees on increasing the enterprise's value (financialization) and target achievement. This goes hand in hand with centralized strategic decisions and operative decentralization, controlled via the company's strategic objectives [3: 135].

Discretion rises regarding communicative interfaces inside and outside the enterprise being modeled by the employees - demanding translations of economic logic and symbols into different contexts [5: 6f.]. This increasingly requires the ability to reflect connections, knowledge of business processes and a competence of organizing creatively [2: chp. 3.4] so that aspects of self-employment also become integrated in vocational training curricula.

Several aspects of commercial thinking and acting are discerned: on the basic level of concrete transactions merchants' thinking and acting is marked by communicative and interactive tasks, use of planning, organizing, regulating, documenting and balancing instruments and systems, thus constituting situations and interactions with binding character influenced by typical spheres of activities [9]. They consider company-specific conditions, aims and processes as well as external ties to markets, relevant political trends and applicable laws [5: 10].

\section{Methodology}

A document-analysis of the curricula of 55 initial and 33 further trainings in commercial and business service occupations regarding their commonalities and differences was carried out. It is now possible to say which contents are learned in which contexts and institutions, what their impact on the vocational qualification is and how they are examined. This analysis was complemented by a historical and a sociological literature-study $[3,7]$.

This paper focuses on the analysis of data from a follow-up study to the German BIBB/BAuA Employment Survey 2012 of employees in commercial and business service occupations. With this analysis we intend to gain deeper understanding on tasks, skills and self-images of service-workers as well as their demand for further qualification and their future prospects. It was conducted as a CATI-survey (Computer Assisted Telephone Interview). A sample of 2.304 employees in 10 relevant occupational groups is covered. The survey connects to results of the document-analysis and the literature-studies.

The sample was stratified into 10 occupational groups. These groups were clustered according to how well their contents matched. The starting points for the grouping were initial and further vocational training occupations for which a content analysis (see below) produced comparable contents. A number of actual occupations for which there does not exist a "direct" training (there are about 350 VET occupations in the dual system, compared to more than 2,500 classified occupations and roughly 30,000 occupations overall) were linked to these training occupations, again drawing on comparable contents. The stratification enabled us to draw a sample holding information on all relevant occupations.

\section{Results and conclusion}

Following, we will describe results of the follow-up study. First we will stay on the level of individuals and explore how employees see their work in commercial and business service occupations. In a second step we will focus on the meso-level of occupations and present findings of the analysis of aggregated data. Throughout, the connections to the literature study and the content analysis will be shown.

\subsection{Service occupations as seen by employees}

A central result of the content analysis was a system of categories structuring subject matters and competencies in commercial vocational trainings. „Commercial communalities“, „commercial specialties“, „,comprehensive qualifications“, and „noncommercial qualifications" are differentiated. Within the 55 vocational trainings there are $69 \%$ of communalities - at least on a high aggregation level. The share of specialties lies around $13 \%$. Comprehensive qualifications, not containing any specificities, hold a share of $15 \%$. Lastly there are $3 \%$ of non-commercial qualifications. The following subject matters and fields of action show the highest 
shares: accounting and controlling, marketing, information and communication as well as law and contracts.

So far we can draw conclusions on the commercial profile of singular occupations as well as, based on these profiles, grouped occupations. We can also deduce evidence on different levels of initial and further vocational trainings plus improve concepts of linking initial and further vocational trainings.

Table 1. Occupational groups with their share in all business and commercial service employees

\begin{tabular}{|l|r|}
\hline Group & Share \\
\hline Traders & 5.9 \\
\hline Sales staff & 12.9 \\
\hline Financial service workers & 8.1 \\
\hline Service traders & 4.9 \\
\hline Civil service & 14.1 \\
\hline Other service workers & 8.9 \\
\hline Clerical assistants & 10.6 \\
\hline Management & 12.5 \\
\hline Specialized traders & 7.1 \\
\hline Desk work & 15.0 \\
\hline
\end{tabular}

Source: Follow-up study on commercial and business service occupations to the BIBB/BAuA Employment Survey 2012, weighted values, own calculations

The respondents in the study can be clustered into said 10 occupational groups according to comparable qualificational requirements in initial and continuing vocational trainings. These groups are listed in Table 1 with their shares in all employees in business and commercial service occupations.

Table 2 gives an overview on how well trained and held jobs match. For most groups the majority of employees completed a comparable training, i.e. a training in a job out of one the 10 groups. Interestingly management has the second lowest share of people with a comparable training, following other service workers. Sales staff and specialized trades also have below average shares. This is complemented by respondents' assessments on how well their occupational trainings prepared them for doing their current job. While overall around two thirds think their training does either still have something to do with their current job or largely corresponds to it, people working as sales staff or other service workers do less often think so. Yet, of those working in management nearly three quarters think their trainings prepared them well for their current jobs.
Table 2. Shares of employees trained in a comparable occupation

\begin{tabular}{|l|r|r|r|}
\hline Group & \multicolumn{2}{|l|}{$\begin{array}{l}\text { Trained in a } \\
\text { comparable } \\
\text { occupation? }\end{array}$} & $\begin{array}{l}\text { VET at least } \\
\text { somewhat } \\
\text { prepared for } \\
\text { held job }\end{array}$ \\
\hline & No & Yes & \\
\hline Traders & 26.1 & 73.9 & 66.9 \\
\hline Sales staff service & 41.2 & 58.8 & 51.1 \\
\hline $\begin{array}{l}\text { Financial } \\
\text { workers }\end{array}$ & 15.6 & 84.4 & 74.5 \\
\hline Service traders & 32.0 & 68.0 & 66.8 \\
\hline Civil service & 20.5 & 79.5 & 74.8 \\
\hline Other service workers & 59.3 & 40.7 & 51.4 \\
\hline Clerical assistants & 22.4 & 77.6 & 71.3 \\
\hline Management & 51.8 & 48.2 & 73.3 \\
\hline Specialized traders & 34.5 & 65.5 & 67.0 \\
\hline Desk work & 20.3 & 79.7 & 64.4 \\
\hline Overall & 32.2 & 67.8 & 66.3 \\
\hline
\end{tabular}

Source: Follow-up study on commercial and business service occupations to the BIBB/BAuA Employment Survey 2012, weighted values, own calculations

Descriptive analyses of the quantitative data give some insight on activities, skills and self-concepts in commercial and service occupations. The survey shows that all commercial employees accomplish tasks regarding the company's accounting in terms of accounting documentation. On average, tasks as accounting business (49.6\%) or payment (62.8\%) transactions are carried out by at least half of the employees. Furthermore, these and other tasks in the field of accounting and controlling are regarded as typically mercantile by more than $70 \%$ of commercial employees. Other tasks are being carried out less often or less regular and also regarded as service-tasks more often.

The evaluation of controlling data is to some extent part of employees' tasks (52.9\%). This validates the outstanding role corresponding learning contents in "commercial accounting and controlling" have within the curricula.

The survey indicates that all groups of commercial employees need basic knowledge in the areas of contract law (46.9\%), employment law (49.0\%), corporate law $(43.2 \%)$ and tax law $(37.1 \%)$.

This also validates the findings of the curriculaanalysis. The same applies to the area "information and communication", which is also an important part of the curricula. Regarding this $96.8 \%$ of the employees state that communicative skills are 'very important' or 'important' for their occupation. This goes together with another $94.0 \%$ of employees stating that problemsolving skills are at least 'important' for their occupations. While problem-solving and 
communicative skills are seen as important, skills in the areas of economic frame conditions $(70.9 \%)$ and skills in marketing and distribution $(65.2 \%)$ are seen as 'less important' or 'unimportant'.

For those skills that are regarded as important or very important, respondents were asked to indicate where they have acquired them. Our assumption is that commercial knowledge and skills cannot be learned only on the job. The survey shows that skills can be clearly separated into those learned mainly institutionally (in vocational schools) or in (continuing) training courses. Skills and knowledge in the fields of "foreign languages", "economic frame conditions" or "operative accounting" are mostly learned in schools. Skills in "law and contract" are acquired equally often in school, courses and on the job. The more operative the required skills become, the more often they are learned on the job. But even then at least one out of 10 have acquired their skills in vocational schools. For most skills a grounding seems to have been set in vocational schools which was then extended on the job.

If job-duration is controlled for, the three skill areas primarily learned in vocational schools remain the same, only the area of law and contract moves into this group as well for those who's training is less than 5 years ago. So far the assumption that commercial knowledge and skills cannot be learned only on the job, but need a systematical instruction within vocational school or other courses could only beproved gradually.

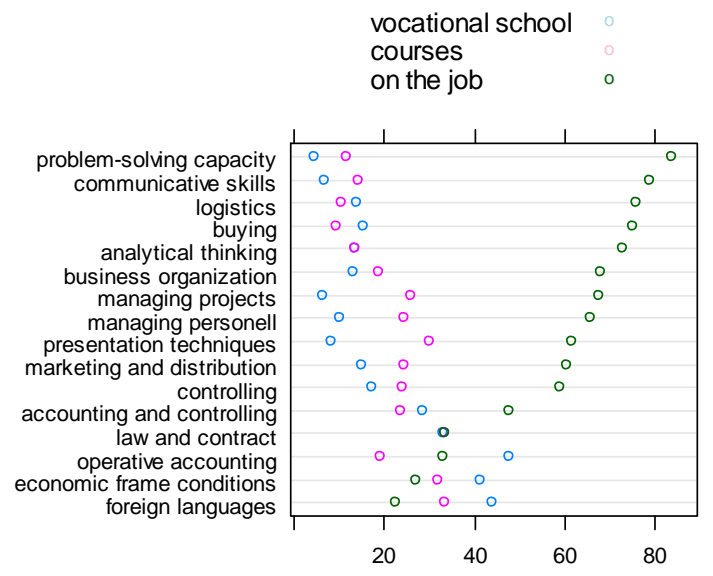

Source: Follow-up study on commercial and business service occupation to the BIBB/BAuA Employment Survey 2012

\section{Figure 1. Where have skills been acquired?}

The assumption that the self-concept of commercial employees is formed by customer- and marketorientation is supported by the data. Respondents were asked to indicate which type of job-titles could best describe their self-perception. Although $85.1 \%$ of commercial and business service workers did see themselves as "service providers", also more than three quarters saw themselves as "organisers" (78.0\%) or "consultants" (75.8\%). The answers were condensed into a simple index. If an employee had given more operating descriptors, he or she was indexed as having an "operative" self-concept. If marketing descriptors prevailed, he or she was indexed as having a "marketing" self-concept. If both were balanced, persons were indicated as having a "neutral" selfconcept. Overall, $62.2 \%$ of service employees see themselves as marketing people, whereas only $11.1 \%$ perceive themselves as operative people. One in four is neutral to these concepts.

The occupation one has might of course correlate with these self-concepts. It can be seen that marketing self-concepts especially prevail in groups like sales staff $(83.3 \%)$, traders $(77.2 \%)$ and also financial service workers $(73.5 \%)$. The operative conception is held most often in clerical assistants and accounting clerks $(23.2 \%)$ and in desk work occupations (19.9\%).

It is interesting to note here that what employees in commercial and business service occupations aim at in their work is for $65.6 \%$ to realize a profit (on the level of the firm), only $17.9 \%$ act according to surrounding conditions. This was found by a factor analysis of different aspects which could influence the employees' work, after which an index was built to extract their overall working motives. From those who aim at realizing profits, $70.0 \%$ also see themselves as marketing people.

Finally, the assumption that commercial employees have room for designing their own work proceedings but not regarding the business processes of their enterprise could be confirmed. $78.2 \%$ of the respondents work autonomous and only $7.0 \%$ of them work according to orders. Also, $79.3 \%$ of the respondents autonomously plan their own work. Over two thirds $(69.5 \%)$ of commercial and business service workers have great scope for organizing their work. Regarding the instruments used $38.3 \%$ have great scope and $34.9 \%$ medium scope. Notably, specialized traders $(78.0 \%)$ and traders $(72.0 \%)$ have great scope for organizing their work, just as those in the management group have, although they have the highest autonomy with $84.9 \%$. Most service employees only have low influence on the business processes of their enterprise $(39.6 \%)$.

The data enable us to give a precise overview on respondents' occupational status. With this, we distinguish between low, medium and high qualified positions, along self-employed and others. Others can be helping family members in small firms. We do not separate management positions as such, although most of them will be within high qualified positions. The reason for this lies in the problem of differentiating 
managing from supervising positions. In both a number of employees is supervised, while supervising others, especially in Germany, is also part of medium qualified positions. Inside service-occupations, with people having a paid job of at least 10 hours a week, there are $19.3 \%$ on low qualified positions, $55.5 \%$ on medium qualified positions, $16.2 \%$ on high qualified positions, $8.0 \%$ self-employed and $1.0 \%$ on other positions.

It can be argued that the ratio of specific skills to generic skills one has to apply is defined by one's occupational status. The higher up in the firm's hierarchy, the more important generic skills are. Figure 2 shows grouped box-plots for the share of generic skills according to one's occupational status. It becomes clear that with higher positions, generic skills indeed are more important. The notches to the sides of the boxes indicate that these differences most probably (indicating a 95\% quasi-confidence interval) also pertain in the population. For self-employed though the share of generic skills seems to be lower. This is due to the fact that self-employed also have to cover tasks that otherwise would be carried out by employees on lower positions. Still, self-employed have significantly higher shares of generic skills than workers on low and medium qualified positions.

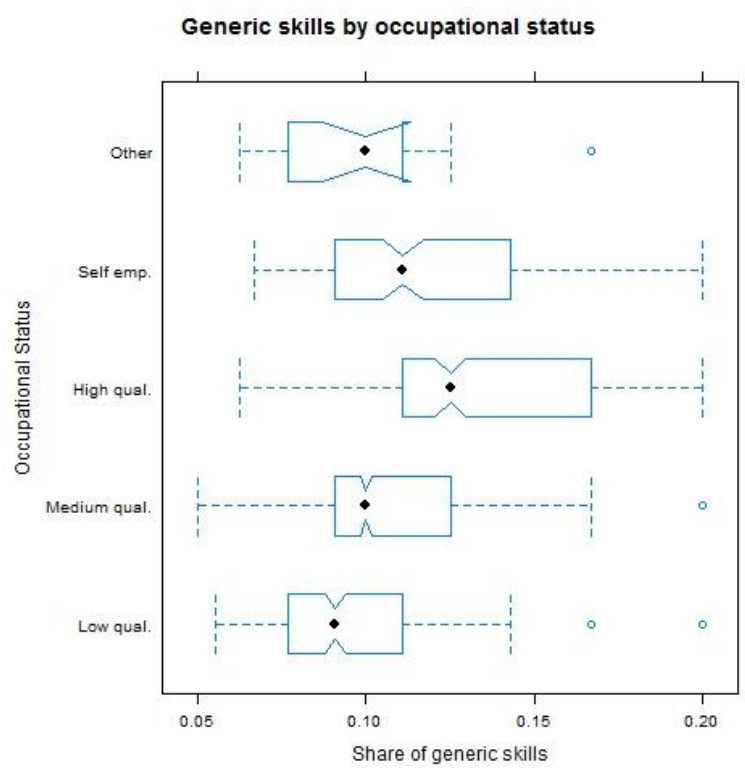

Figure 2. Share of generic skills by occupational status

The degree of autonomy for planning and carrying out one's own work will also differ with occupational status and possibly the occupational group. We built an index ranging from 4 to 12 with higher values meaning higher degrees of autonomy. Respondents were asked to indicate whether they had low, medium or large influence on planning and executing their own flow of work and instruments used and also the in-firm or managerial workflow as well as gateways between their own work and adjacent divisions.

Figure 3 shows the distribution of degrees of autonomy over occupational status. There is a clear trend for working more autonomous on higher positions, with differences in the means being significant. All in all, self-employed, as would be expected, have the highest degrees of autonomy (three quarters of them have at least medium influence on every aspect of the autonomy-index). Still, there are no significant differences between self-employed and employees on high qualified positions. This reflects what the literature studies found about the self-image of workers in commercial and business service occupations, showing a high degree of responsibility and affiliation while at the same time working autonomously.

\section{Degree of autonomy by occupational status}

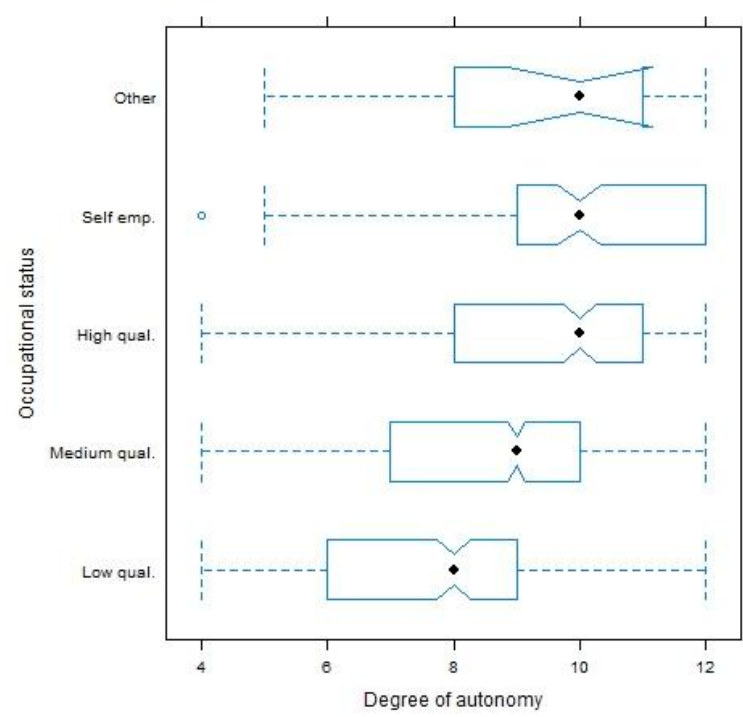

Figure 3. Degree of autonomy by occupational status

Wage has been surveyed in the main questionnaire of the German BIBB/BAuA Employment Survey as monthly gross income. Some respondents did not want to tell their wage. For these and in cases where unreasonably high or low figures were given, income was imputed [8: 13f.]. To arrive at an hourly income, the monthly gross income was divided by the number of actual working hours. Mean hourly wage lies around Euro 19.01 , with the maximum hourly wage reaching Euro 200.00. 


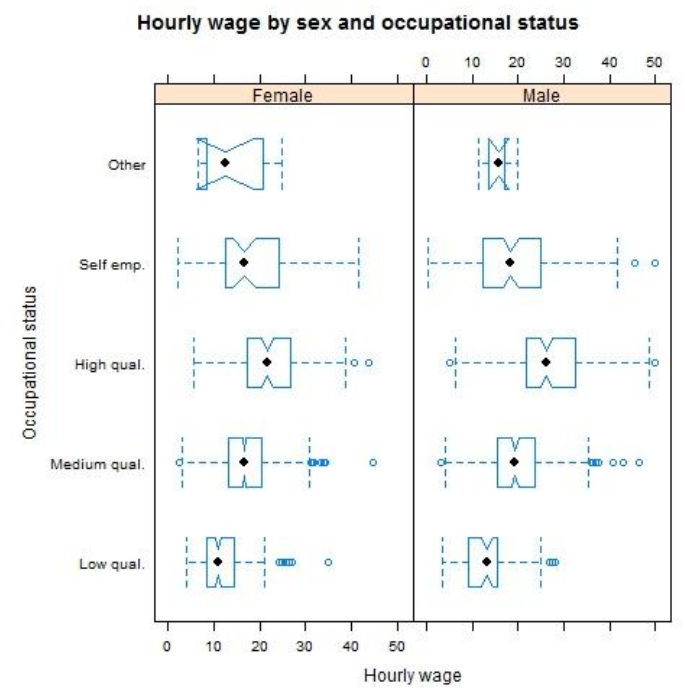

Figure 4. Hourly wage by sex and occupational status

Figure 4 shows that occupational status does have a clear effect on hourly wage. Interestingly, selfemployed in the mean tend to earn less than employees in high qualified positions. Differences between female and male workers seem to exist (especially on positions for high qualified) but do not seem to be too large.

Often gender is seen as a major differentiation. Following the literature studies two hypotheses were derived regarding differences between male and female workers in service occupations. Differences in wages as well as chances for professional development were seen to be driven by occupational status, autonomy and economic sector, rather than gender. Occupational status denotes the individuals' position within the firm, described by qualificational requirements. Autonomy is an index showing in how far employees can structure and plan their working activities by themselves. Two regressions were run to test the hypotheses of non-influence of gender on wage and chances for professional development.

Table 3 shows the results of a linear regression on hourly wage. It can be seen that indeed economic sector and occupational status have highly significant influences, with the estimate for autonomy being not significant. Still, the influence of gender is large and also highly significant. Occupational status (for employees in high-qualified positions and selfemployed) and being male show the largest coefficients. In comparison, the influence of sector and autonomy is marginal. For wage the hypotheses that gender has no influence can only be rejected.
Table 3. Estimates for linear regression on hourly wage

\begin{tabular}{|c|c|c|c|c|c|}
\hline & Estimate & Std. Error & $\mathrm{t}$ value & $\operatorname{Pr}(>|t|)$ & \\
\hline (Intercept) & 12.1926 & 1.0865 & 11.222 & $<2 \mathrm{e}-16$ & **** \\
\hline $\begin{array}{l}\text { Male } \\
\text { (Female) }\end{array}$ & 3.3956 & 0.4757 & 7.139 & $1.34 \mathrm{e}-12$ & $* * *$ \\
\hline \multicolumn{6}{|c|}{ Occupational status (low qualified jobs) } \\
\hline $\begin{array}{l}\text { Medium } \\
\text { qual. }\end{array}$ & 4.3477 & 0.6464 & 6.726 & $2.31 \mathrm{e}-11$ & **** \\
\hline High qual. & 10.7190 & 0.8157 & 13.140 & $<2 \mathrm{e}-16$ & **** \\
\hline $\begin{array}{l}\text { Self- } \\
\text { employed }\end{array}$ & 7.5023 & 0.9643 & 7.780 & $1.18 \mathrm{e}-14$ & **** \\
\hline Other & 1.2993 & 2.3696 & 0.548 & 0.583546 & \\
\hline Autonomy & 0.1295 & 0.1076 & 1.203 & 0.229051 & \\
\hline \multicolumn{6}{|c|}{ Economic sector (civil service) } \\
\hline Industry & 2.6154 & 0.7490 & 3.492 & 0.000491 & **** \\
\hline $\begin{array}{l}\text { Skilled } \\
\text { crafts and } \\
\text { trades }\end{array}$ & -4.1890 & 1.0141 & -4.131 & $3.77 \mathrm{e}-05$ & **** \\
\hline Commerce & -3.2412 & 0.6936 & -4.673 & $3.18 \mathrm{e}-06$ & **** \\
\hline $\begin{array}{l}\text { Other } \\
\text { services }\end{array}$ & 0.2150 & 0.6594 & 0.326 & 0.744425 & \\
\hline Other areas & 0.3867 & 1.1279 & 0.343 & 0.731724 & \\
\hline $\begin{array}{l}\text { Private } \\
\text { Household }\end{array}$ & -4.2922 & 2.0417 & -2.102 & 0.035664 & * \\
\hline NA & -2.7392 & 2.5077 & -1.092 & 0.274842 & \\
\hline \multicolumn{6}{|c|}{$\begin{array}{l}\text { Signif. codes: } 0 \text { '***' } 0.001 \text { '**' } 0.01 \text { '*' } 0.05 \text { '.' } 0.11^{\prime \prime} 1 \\
\text { Adjusted R-squared: } 0.2257 \\
\text { F-statistic: } 43.52 \text { on } 13 \text { and } 1884 \mathrm{DF} \text {, p-value: }<2.2 \mathrm{e}-16 \\
\text { Source: Follow-up study on commercial and business service } \\
\text { occupations to the BIBB/BAuA Employment Survey 2012, own } \\
\text { calculations }\end{array}$} \\
\hline
\end{tabular}

According to the literature studies and the theory developed within the project it was hypothesized that the chances for professional development were mediated by occupational status, autonomy and sector as well. Chances for professional development are operationalized with an index of satisfaction with chances for promotion and further education, weighed by overall satisfaction with the working situation. The more satisfied a person is with his or her overall working situation, the more positive chances weigh. The index ranges from 0 (very high satisfaction with chances for professional development) to 4 (not satisfied at all), the mean being 1.638, indicating that most respondents are rather contempt with their chances for professional development.

Table 4 shows the results of another linear regression. Following the hypothesis, the same influences as with wage were tested. Again, occupational status (high qualified positions and selfemployed) shows large coefficients. The influence of autonomy ranges from $0.07 * 4=0.28$ (for those with least autonomy) to $0.07 * 12=0.84$ index-points (for those with most autonomy). This is a high and significant influence. The influence of gender is less significant and rather low. For chances for professional development it can be assumed that gender indeed has no (or only a marginal) effect. It has to be noted, though, that the model itself performs rather poorly, 
with the adjusted $\mathrm{R}^{2}$ showing that only 9 percent of the variance is explained by the model.

Table 4. Estimates for linear regression on chances for professional development

\begin{tabular}{|c|c|c|c|c|c|}
\hline & Estimate & $\begin{array}{l}\text { Std. } \\
\text { Error }\end{array}$ & $\begin{array}{l}\mathrm{t} \\
\text { value }\end{array}$ & $\operatorname{Pr}(>|t|)$ & \\
\hline (Intercept) & 0.88620 & 0.09921 & 8.933 & $<2 \mathrm{e}-16$ & **** \\
\hline Male(Female) & -0.10630 & 0.04341 & -2.449 & 0.01443 & * \\
\hline \multicolumn{6}{|c|}{ Occupational status (low qualified jobs) } \\
\hline Medium qual. & 0.17531 & 0.05903 & 2.970 & 0.00302 & *** \\
\hline High qual. & 0.41365 & 0.07449 & 5.553 & $3.2 \mathrm{e}-08$ & **** \\
\hline Self-employed & -0.45037 & 0.08780 & -5.130 & $3.2 \mathrm{e}-07$ & **** \\
\hline Other & -0.00254 & 0.21640 & -0.012 & 0.99066 & \\
\hline Autonomy & 0.07322 & 0.00983 & 7.451 & $1.4 \mathrm{e}-13$ & 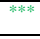 \\
\hline \multicolumn{6}{|c|}{ Economic sector (civil service) } \\
\hline Industry & 0.05871 & 0.06832 & 0.859 & 0.39028 & \\
\hline $\begin{array}{l}\text { Skilled crafts } \\
\text { and trades }\end{array}$ & 0.10573 & 0.09261 & 1.142 & 0.25375 & \\
\hline Commerce & 0.07512 & 0.06334 & 1.186 & 0.23575 & \\
\hline Other services & 0.00297 & 0.06021 & 0.049 & 0.96068 & \\
\hline Other areas & 0.04448 & 0.10299 & 0.432 & 0.66594 & \\
\hline $\begin{array}{l}\text { Private } \\
\text { household }\end{array}$ & -0.27617 & 0.18646 & -1.481 & 0.13873 & \\
\hline NA & -0.28683 & 0.22900 & -1.253 & 0.21054 & \\
\hline \multicolumn{6}{|c|}{$\begin{array}{l}\text { Signif. codes: } 0 \text { '***' } 0.001^{\prime} * * ' 0.01 \text { '*' } 0.05 \text { '.' } 0.1^{\prime} \text { ' }^{\prime} 1 \\
\text { Adjusted R-squared: } 0.09007 \\
\text { F-statistic: } 15.48 \text { on } 13 \text { and } 1888 \mathrm{DF} \text {, p-value: < } 2.2 \mathrm{e}-16 \\
\text { Source: Follow-up study on commercial and business service } \\
\text { occupations to the BIBB/BAuA Employment Survey } 2012 \text {, own } \\
\text { calculations }\end{array}$} \\
\hline
\end{tabular}

Notably, the influence of the occupational groups is not tested in the above models. This was done (results available on request) and results showed that occupational groups explained most of the variance with all other influences largely decreasing or even vanishing. This can be explained with how the occupational groups were built and shows that the grouping itself differentiates commercial and business service occupations very well.

\subsection{Relating service occupations to each other}

So far we have shown how employees in commercial and business service occupations see and describe their jobs. This reveals a number of similarities between said occupations. In order to get a clearer idea about which contents constitute these occupations (as held occupations) and establish relations between held service jobs (as opposed to the findings of the content analysis of trainings) we conducted a principal components analysis on a number of variables holding aggregated data on the level of the 10 occupational groups.

Regarding the principal components analysis we will report results of the first two components (in sum explaining $63.68 \%$ of the initial variance). These components can also be seen as dimensions spanning a room in which the occupational groups can be plotted according to how they relate to the variables.

The first dimension is best described as consisting of basic mercantile tasks. These can be seen as weighted by their process- or project-orientation. The more "singular" tasks become (like with handling costumer complaints) the lower their score on this dimension. The second dimension is basically described by what influences the work. Do employees try to realize profits or is their work lead by acting according to frame conditions? Table 5 shows variables with the highest loadings on the first two dimensions (full results available upon request).

Table 5. Descriptions of dimensions

\begin{tabular}{lr}
\hline Variable & $\begin{array}{c}\text { Loading on } \\
\text { dimension 1 }\end{array}$ \\
\hline Analyze controlling data & 0.9699 \\
Set up a budget & 0.9680 \\
Calculate & 0.9274 \\
Negotiate contract terms & 0.8958 \\
Knowledge in contract law & 0.8676 \\
Set up marketing strategies & 0.8546 \\
Skills in business organization & 0.8458 \\
Organize projects & 0.8173 \\
Controlling & 0.8040 \\
\hline & Loading on \\
& dimension 2 \\
\hline Realize profits & 0.7498 \\
Buying & 0.7371 \\
Skills in presentation techniques & 0.7275 \\
Account transactions & -0.6324 \\
Knowledge in tax law & -0.7716 \\
Act according to frame conditions & -0.7734 \\
\hline Source: Follow-up study on commercial and business \\
service occupations to the BIBB/BAuA Employment \\
Survey 2012, weighted values, own calculations
\end{tabular}

Given these dimensions the occupational groups can be plotted as in Figure 5. It becomes clear that management occupations as well as specialized traders and service traders have higher shares of projectoriented contents. On the other hand, desk work occupations show far lower shares here. It is interesting to note that the extreme positions on this first dimension of basic mercantile tasks are held by occupational groups in which the share of those working in a job comparable to their occupational training is below average. Sales staff and other service workers are also feeling less well prepared by their trainings for their current jobs (resulting in negative values on this dimension), while management personnel's share of feeling well prepared is above average (resulting in positive values on this dimension).

Also, the occupational groups are clearly discerned by what influences the work: be it profit-orientation (as 
for traders) or acting according to frame conditions (as for civil service workers or clerical assistants).

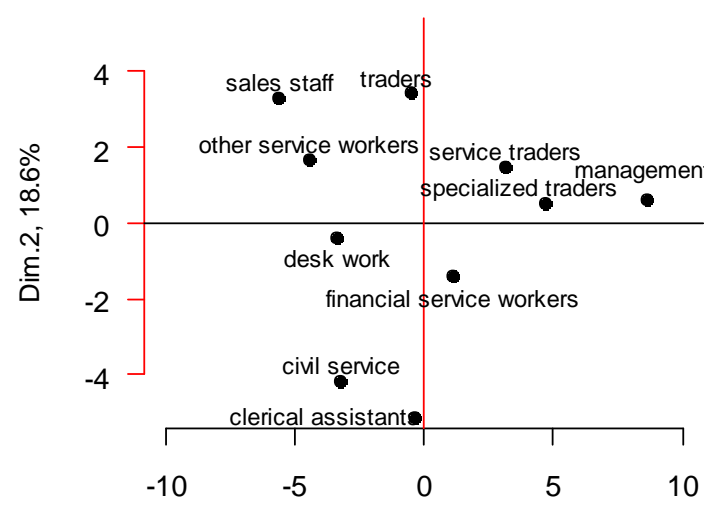

Dim.1, 45.08\%

Figure 5. Plot of occupations according to their contents

\subsection{Conclusion}

Preceding studies within the project on "similarities and differences between commercial and business service occupations" found a common core of comparable qualifications and contents of these jobs. Supplemented by literature and theoretical studies a number of assumptions on what constitutes these service occupations as held occupations were drawn.

In a follow-up study to the German BIBB/BAuA Employment Survey 2012 for employees holding one of these occupations statistical data was drawn with which the assumptions could be tested. Results of the follow-up study confirm most of these assumptions. Employees working in commercial and business service occupations show clear trends regarding selfconcepts or aims of their work. But as for single tasks and skills it becomes clear that there are differences between several groups of service occupations. These are mainly coined by tasks, scope of organizing and the position within the firm.

A principal component analysis on the level of occupational groups showed how well these occupations can be discerned by (the projectorientation of) their basic mercantile contents and the aims governing the work, be it profit-orientation or acting on frame conditions. It also becomes clear how held jobs relate to how well prepared employees feel for their basic mercantile and project-oriented tasks. Hypothesized gender differences could only be proven for hourly wage, but not for chances for professional development.

As the project aims at building a framework for describing commercial and business service occupations, being able to define common cores and relevant differences, another important finding is that the grouping of service occupations within the project worked well. This forms the ground for tackling the challenges on relevant training occupations within the German Dual System efficiently and well informed.

\section{References}

[1] Boes, A./Kämpf, T. (2010): Dawning of a new era in the office: clerical work and globalization. Original title: Zeitenwende im Büro: Angestelltenarbeit im Sog der Globalisierung. In: WSI Mitteilungen, H. 12, $63 \mathrm{Jg}$.

[2] Brater, M./Freygarten, S./Rahmann, E./Rainer, M. (2011): Art as acting - acting as art. Lessons to be learned from artists for the world of work and vocational education. Original title: Kunst als Handeln - Handeln als Kunst. Was die Arbeitswelt und Berufsbildung von Künstlern lernen können. Bielefeld

[3] Haipeter, T. (2011): Clerical workers: from accountants to service workers - a sociological investigation. Original title: Kaufleute zwischen Angestelltenstatus und Dienstleistungsarbeit - eine soziologische Spurensuche. Wissenschaftliches Diskussionspapier des BIBB, Nr. 126, Bonn

[4] Hall, A./Siefer, A./Tiemann, M. (2012): BIBB/BAuA Employment Survey of the Working Population on Qualification and Working Conditions in Germany 2012, suf_1.0. Research Data Center at BIBB (ed., data access). Federal Institute for Vocational Education and Training. Bonn. doi:10.7803/502.12.1.1.10

[5] Kaiser, F.: What defines clerks? Their occupational thinking and acting in historical, sociological and regulative perspective. Original title: Was kennzeichnet Kaufleute? Ihr berufliches Denken und Handeln aus historischer, soziologischer und ordnungspolitischer Perspektive. In: Faßhauser, U./ Fürstenau, B./ Wuttke, E.: Berufs- und wirtschaftspädagogische Analysen. Opladen 2012, S. 165178.

[6] Kotthoff, H. (1997): Managers and changing coporate cultures. Would-be-entrepreneurs or employers? Original title: Führungskräfte im Wandel der Firmenkultur. QuasiUnternehmer oder Arbeitgeber? Berlin

[7] Reinisch, H. (2011): A History of mercantile occupations. Original title: Geschichte der kaufmännischen Berufe. Wissenschaftliches Diskussionspapier des BIBB, Nr. 125, Bonn

[8] Rohrbach-Schmidt, D./Hall, A. (2013): BIBB/BAuA Employment Survey 2012. Daten- und Methodenbericht Nr. 1/2013, English version. Online: http://www.bibb.de/dokum ente/pdf/Daten-

_und_Methodenbericht_ETB12_EN_Version.pdf (29.07.2013) 
[9] Tramm, T. (2009): Development of occupational competences in the context of mercantile work- and business-processes. Original title: Berufliche Kompetenzentwicklung im Kontext kaufmännischer Arbeitsund Geschäftsprozesse. In: Brötz, R. / Kaiser F. (ed.): Anforderungen an kaufmännisch-betriebswirtschaftliche Berufe aus berufspädagogischer und soziologischer Sicht, Bonn

[10] Voss-Dahm, D. (2009): On the stability of social inequalities in businesses: work in retail sale. Original title: Über die Stabilität sozialer Ungleichheit im Betrieb: Verkaufsarbeit im Einzelhandel. Berlin

[11] Weber-Menges, S. (2004): Working class or employees? Comparative empirical analysis on status, chances, and lifestyle of workers and clerks in industries. Original title: Arbeiterklasse oder Arbeitnehmer? Vergleichende empirische Untersuchungen zu Soziallage, Lebenschancen und Lebensstilen von Arbeitern und Angestellten in Industriebetrieben. Wiesbaden 